\title{
Terapia de grupo cognitivo-comportamental com agressores conjugais
}

\section{Cognitive behavioral group therapy with batterers}

\author{
Mirian Béccheri CORTEZ \\ Ricardo da Costa PADOVANI \\ Lúcia Cavalcanti de Albuquerque WILLIAMS ${ }^{3}$
}

\begin{abstract}
Resumo
Muitas características foram apontadas em relação a agressores conjugais, tais como: ciúme, baixa auto-estima, insegurança, minimização e negação da violência. A teoria da aprendizagem social de Bandura focaliza o papel do ambiente na aquisição, manutenção e modificação de respostas agressivas. Uma revisão da literatura brasileira realizada pelos autores indicou poucos trabalhos direcionados a agressores. Este estudo objetivou avaliar a eficácia de um grupo psicoterapêutico cognitivo-comportamental para agressores conjugais, buscando eliminar ou reduzir sua violência. Sete homens denunciados por agredirem suas parceiras participaram deste estudo. Os temas e as técnicas utilizados foram: assumir responsabilidade pela agressão, controle da raiva, role-playing e time-out. Realizaram-se oito sessões, sendo uma por semana (com duas horas de duração cada uma), durante dois meses. Os resultados foram avaliados por meio de entrevistas, questionários, Escala de Táticas de Conflito e relatos recolhidos no pré- e pós-teste e em três períodos de "follow-up" de três, seis e doze meses. Os resultados apontam para a redução das agressões, tendo sido registrados dois casos de reincidência.
\end{abstract}

Palavras-chave: agressão; psicoterapêutico; terapia cognitivo-comportamental; violência doméstica.

\begin{abstract}
Many batterers' characteristics have been described, such as: jealousy, low self-esteem, insecurity and denial of violent behavior. Bandura's social learning theory emphasizes the influence of the social environment on the aggressive behaviors acquisition, maintenance and development. The Brazilian authors' literature review did not find enough systematic and specific projects for batterers. The goal of this study was to appraise a cognitive-behavioral group therapy efficiency for batterers, in order to reduce aggressive behaviors. Seven men who had been charged with wife assault participated of the study. The themes and techniques used were: taking responsibility for the aggression anger management, role-playing and time-out. There were eight two-hour weekly sessions for two months. The results were analyzed from the interviews, pre and post test questionnaire responses (Conflict Tactics Scale) and three moments of Follow-up (three, six and twelve months after the process). According to this evaluation, the study's goals were achieved. Two reincidence episodes were registred.
\end{abstract}

Key words: aggression; cognitive-behavior therapy; group therapy; family violence.

$\boldsymbol{\nabla V} \nabla \mathbf{v}$

1 Bolsista de iniciação científica da FAPESP. Departamento de Psicologia, Universidade Federal de São Carlos. São Carlos. SP. Brasil.

2 Bolsista Pró-Reitoria de Extensão, Departamento de Psicologia, Universidade Federal de São Carlos. Rodovia Washington Luís (SP-310), km 235, 13565-905, São Carlos, SP, Brasil. Correspondência para /Correspondence to: R.C. PADOVANI. E-mail: <padova_200275@yahoo.com.br>.

3 Departamento de Psicologia, Universidade Federal de São Carlos. São Carlos. SP. Brasil. 
Muitas características já foram descritas a respeito de homens que agridem suas companheiras, sejam elas esposas ou não. Entre tais características estão: isolamento social, ciúme, baixa auto-estima (Sinclair, 1985; Rynerson \& Fishel, 1993; Hamberger \& Holtzworth-Munroe, 1999; Soares, 1999), uso abusivo de álcool ou drogas (Sinclair, 1985; Rynerson \& Fishel, 1993; Gondolf, 1993; 1996a; 1996b; 1997; Jasinski \& Williams, 1998; Soares, 1999), insegurança, possessividade, o fato de possuírem visões estereotipadas sobre papéis de gênero (Sinclair, 1985; Soares, 1999), podendo apresentar, ainda, problemas de personalidade, histórico de violência na infância (Sinclair, 1985; Rynerson \& Fishel, 1993; Gondolf, 1993; 1996a; 1996b; 1997; Jasinski \&Williams, 1998), depressão e ansiedade (Hamberger \& Holtzworth-Munroe, 1999). Um aspecto muito característico dos agressores é a tendência à minimização da agressão e/ou negação do comportamento agressivo, culpando a vítima pelo seu comportamento (Sinclair, 1985; Faulkner, Stoltenberg, Cogen, Nolder \& Shooter, 1992; Gondolf, 1993; Rynerson \& Fishel, 1993; Hamby, 1998; Hamberger \& Holtzworth-Munroe, 1999).

Grande parte dos incidentes de agressão ocorre quando as dificuldades advindas das características acima se associam a fatores estressores, tais como: dificuldades financeiras (Faulkner et al., 1992; Soares, 1999), desemprego (Sinclair, 1985; Faulkner et al., 1992), conflitos intrafamiliares ou com a lei (Faulkner et al., 1992). Esses fatores são, por assim dizer, o estopim para que o comportamento violento se desencadeie, mas não devem ser vistos como causas principais ou unilaterais de tal comportamento.

Contribuindo para a ocorrência e perpetuação dos comportamentos agressivos do homem dentro da família estão a conivência e, de certa forma, o estímulo por parte da sociedade à exibição de força e agressividade masculinas (Sinclair, 1985). O fato de essa agressão ser dirigida à companheira revela, ainda, a discriminação social em relação à mulher, principalmente quando ela está no papel de esposa (Sinclair 1985; Saffioti, 1997). A impunidade dos agressores permite que esse comportamento abusivo se perpetue (Saffioti, 1997). Dados de um levantamento de 178 denúncias nas Delegacias de Defesa da Mulher (DDM), em São Paulo, mostraram que uma parte mínima dessas
(2\%) chega à condenação; 70\% dos casos são arquivados em grande parte por desistência da vítima que muda o depoimento e, em 21\% dos casos julgados, os acusados são absolvidos (Saffioti, 1999). Comprovando a dificuldade de levar uma denúncia a julgamento, um estudo desenvolvido por Williams (2001a) encontrou 100\% de arquivamento nos casos acompanhados na DDM de São Carlos.

A teoria social da aprendizagem (Bandura, 1973) é de grande importância para a compreensão da agressividade humana na medida em que focaliza o papel do ambiente social na aquisição, manutenção e modificação das respostas agressivas. Bandura, Ross e Ross (1961) comprovaram a tendência de crianças à imitação de um modelo agressivo, ocorrendo um aumento na freqüência de agressões quando o modelo apresentado era do mesmo sexo. No caso de meninos, a tendência a imitar era maior do que as meninas, o que, segundo os autores, se devia ao fato de o comportamento agressivo por parte dos homens ser mais aceito socialmente. Nesse sentido, Wexler (1999) afirma que as pesquisas têm indicado que homens que presenciaram brigas entre os pais apresentavam de três a quatro vezes mais probabilidade de agredirem suas esposas.

Muitos autores adotam a noção de que a violência pode ser transmissível de geração em geração, como é o caso de Sinclair (1985), que afirma que "o indivíduo aprende a violência pela cultura". Essa visão possibilita novas formas de tratamento e o direcionamento a tópicos que envolvam desde o controle da raiva até trabalhos sobre o questionamento de mitos e de pensamentos errôneos direcionados à própria parceira e ao relacionamento homem-mulher.

Soares (1999) acredita que, com a possibilidade de tratamento, o homem agressor passou a ser visto como uma vítima legal e moralmente responsável pelo abuso e com possibilidade de recuperação. O agressor é considerado, segundo a autora, resultado de um histórico de reações inadequadas ao estresse, abuso prévio ou incapacidade psicológica de se relacionar, possibilitando, desse modo, a elaboração de um modelo para a compreensão da violência e, a partir desse, a criação de programas de intervenção.

A aplicação de grupos terapêuticos é uma das alternativas para o desenvolvimento de um programa 
com agressores (Sinclair, 1985, Faulkner et al., 1992; Soares, 1999), sendo que há muitas diferenças entre os programas aplicados, ocorrendo variações de duração e de abordagem (Gondolf, 1996a; 1996b; 1997; Soares, 1999). De modo geral, esses programas seguem uma diretriz comum que poderia ser identificada dentro da modalidade cognitivo-comportamental, orientada por princípio de gênero (Soares, 1999). Outra característica desse tipo de programa é o fato, como afirma Sinclair (1985), de os grupos serem mais efetivos do que o aconselhamento individual por haver uma possível diminuição de vergonha, culpa e isolamento na interação com os demais membros.

Devido às variações nesses grupos, Gondolf (1996a; 1996b; 1997) realizou um estudo comparativo entre quatro diferentes programas para agressores que tinham como principais variantes: duração da intervenção (de três a nove meses), possibilidade ou não de atendimento complementar (em caso de uso abusivo de substâncias) e atendimento antes ou depois do julgamento. O autor concluiu que os programas curtos e bem estruturados são tão eficientes quanto os mais longos; que agressores "resistentes" devem participar de programas intensivos (três a quatro dias por semana em três meses); e que deve haver acompanhamento do uso de álcool entre os participantes.

Ainda com relação à intervenção com agressores, Faulkner et al. (1992) sugerem a avaliação empírica de um programa de tratamento que corrija dificuldades de assertividade e atitudes relacionadas à intimidade, à reduzida eficácia pessoal, baixa autoestima e níveis crescentes de hostilidade, de ansiedade, culpa e depressão.

Os estudos e programas voltados à violência doméstica no Brasil são poucos e ainda menor a quantidade dos direcionados ao agressor (Padovani \& Williams, 2002). As informações sobre o perfil psicossocial do agressor e possíveis alternativas de tratamento são, por isso, poucas e de difícil acesso, sendo encontradas com mais freqüência em artigos importados, que não condizem completamente com a realidade do Brasil. Essa escassez de dados nacionais aponta para a necessidade de mais pesquisas sobre esse tipo de violência e sobre intervenções a vítimas e autores da agressão.
Essa pesquisa buscou avaliar a eficácia de um grupo psicoterapêutico cognitivo-comportamental para agressores conjugais no sentido de eliminar ou reduzir, significativamente, tal tipo de violência.

\section{Método}

\section{Triagem dos participantes}

Os participantes foram encaminhados ao grupo por policiais da DDM e por estagiários de psicologia do Programa de Intervenção a Vítimas de Violência Doméstica (Williams, 2001 b) que atendiam na DDM e no Conselho Tutelar de São Carlos. Além disso, foi desenvolvido um procedimento de recrutamento voluntário conduzido no Fórum Criminal de São Carlos, no qual casais eram abordados pelos terapeutas ao saírem das audiências, sendo oferecida ao agressor a possibilidade de participar do grupo.

Um primeiro grupo (grupo-piloto), com os participantes encaminhados por meio dos procedimentos acima, não foi concluído devido ao grande número de desistências. Em decorrência, para o desenvolvimento mais efetivo do grupo e maior adesão, uma contingência legal foi introduzida a fim de conduzir participantes ao grupo: um dos juízes das varas criminais da cidade passou a indicar o grupo para o agressor. O critério de inclusão no grupo incluía que o participante convivesse com a parceira e que a violência tivesse sido denunciada.

\section{Participantes}

Participaram do grupo oito homens, sete denunciados por agressão contra suas parceiras (P1, P2, P3, P4, P5, P6 e P7) e um oitavo (P8) que buscou atendimento no Programa de Intervenção a Vítimas de Violência Doméstica da DDM para conseguir "se controlar". Apesar de relatar nunca ter apresentado episódios de agressão contra sua parceira, P8 foi aceito no grupo, mas não respondeu aos instrumentos de medida. Um dos participantes (P6) havia participado do grupo-piloto e passou a receber atendimento individual até que o segundo grupo fosse iniciado, quando, então, passou a integrá-lo. 


\section{Procedimento}

O procedimento do grupo foi fundamentado no modelo terapêutico cognitivo comportamental e baseou-se nos trabalhos de Sinclair (1985), Faulkner, Stoltenberg, Cogen, Nolder e Shooter (1992), Rynerson e Fishel (1993), O'Leary, Heyman e Neidig (1999), Padovani, Marcondelli, Gasparotto e Williams (2001) e Padovani e Williams (2002).

Foram conduzidas oito sessões, sendo uma por semana, com duas horas de duração cada uma (com intervalo de 15 minutos), ao longo de dois meses. Dois terapeutas foram responsáveis pelo grupo: a primeira autora do projeto (na época, graduanda do $4^{\circ}$ ano em psicologia) e um segundo autor, terapeuta do sexo masculino (na época, formando em psicologia) com experiência na área de atendimento a agressores (Padovani \& Williams, 2002) e atendimento em grupo com mulheres vítimas de violência conjugal (Padovani et al., 2001). As sessões foram conduzidas na sala de reuniões do Laboratório de Prevenção e Análise da Violência (LAPREV), situado na UFSCar, durante as manhãs de domingo, por ser esse o período que acomodava o maior número de pessoas. A sala era equipada com cadeiras, mesa e aparelho de som. Os participantes e suas parceiras receberam passes de ônibus para se deslocar até o local de atendimento e/ou entrevista.

O Termo de Consentimento Livre e Esclarecido foi obtido por meio da assinatura de um termo de participação especificando objetivos e normas éticas a serem seguidas no grupo, tais como não divulgação de suas identidades e sigilo das informações concedidas. As parceiras que participaram do acompanhamento assinaram termos especificando suas participações em entrevistas e questionários.

As técnicas utilizadas, que em outros estudos (Sinclair, 1985; Faulkner et al., 1992; O'Leary, Heyman \& Neidig, 1999) se mostraram eficientes e adequadas para o desenvolvimento de grupos com essa população, foram as seguintes: dinâmica de apresentação do grupo, exposição sobre um tema e sua posterior discussão, treino de relaxamento e de assertividade, role-playing, confrontação, time-out, auto-observação e tarefa de casa.

Na dinâmica de apresentação do grupo, era solicitado que cada membro dissesse o nome, idade, profissão e relatar-se um breve histórico do episódio que o levou a participar do grupo. Cada participante tinha em média doze minutos para realizar sua apresentação.

No treino de relaxamento, inicialmente o terapeuta ensinava os participantes a realizarem a devida respiração: o terapeuta orientava que respirassem profundamente contando até três, prendesse o ar contando até três e soltasse o ar contando até três. Eram realizadas mais duas séries do exercício. Posteriormente, era solicitado aos participantes que prestassem atenção aos batimentos cardíacos, dizendo para si mesmo:"agora eu estou calmo, meu coração já não bate tão rápido". Ao finalizar o exercício, o terapeuta pedia para o participante dizer como estava se sentindo naquele momento e o que achava da atividade.

No treino de assertividade os terapeutas explicavam, inicialmente, que diante de uma dada situação poderíamos nos comportar basicamente de três maneiras, que são: passiva, assertiva (adequada) ou agressiva. Era explicitado, ainda, que nossa maneira de se comportar estava sob controle de nossa história de vida e das circunstâncias da situação. Nesse momento, eram dados exemplos de cada um dos tipos de interação social. Posteriormente, os terapeutas apresentavam uma situação hipotética na qual os participantes tinham oportunidade de participar ou observar a representação de papéis referente a cada um dos três tipos de enfrentamento de uma situação-problema (role-playing).

$\mathrm{Na}$ técnica de time-out, era explicitado aos participantes que no momento em que percebessem que poderiam perder o controle (agindo, portanto, de maneira agressiva), poderiam, por exemplo, sair de casa, tomar um banho e/ou conversar com um amigo para evitar o agravamento da situação-problema. Em tal momento era enfatizada a importância da auto-observação (por exemplo, tom da voz, gesticulações, movimentação, batimento cardíaco) para detectar estímulos discriminativos e, portanto, indicativos do comportamento agressivo (verbal e/ou físico). No término da atividade, era discutida a relevância dessa habilidade no manejo de situações problemas e, conseqüentemente, na adequação social. Era, também, ressaltada a importância dessa prática na vida cotidiana e dada orientação de tarefas de casa envolvendo as novas práticas. No início de cada sessão, 
os terapeutas verificavam as tarefas de casa, perguntando quais técnicas trabalhadas haviam sido empregadas e os respectivos resultados.

A descrição resumida das sessões pode ser observada no Quadro 1.

\section{Instrumentos de medida}

Foram utilizados os seguintes instrumentos:

- Escala de Táticas de Conflito Revisada (Conflict Tactics Scale Revised-CTS-2), (Straus, Hamby, Boney-McCoy \& Sugarman, 1996), versão traduzida pelos autores do presente estudo, com autorização do autor Murray Straus, aplicada antes (pré-teste), ao final do grupo (pós-teste) e nos follow-ups.

Os dados referentes ao follow-up foram recolhidos no período de dois a três meses (follow-up 1 - F1), de cinco a seis meses após o término do grupo (follow-up 2 -F2) e um ano após o término do grupo (follow-up 3 - F3).

A CTS-2 mede a extensão de agressões físicas, sexuais, psicológicas e ferimentos por parte de ambos os parceiros, bem como suas habilidades em lidar com conflitos, tendo sido aplicada individualmente nos participantes e em suas parceiras. Durante o pré-teste, pediu-se que as respostas tivessem como referência os seis meses anteriores ao início do grupo. No pós-teste pediu-se que as respostas se baseassem no período em que os participantes faziam parte do grupo e, no follow-up (F1, F2 e F3), as respostas foram dadas com relação ao intervalo de tempo a que cada um deles correspondia: para F1, era considerado o intervalo de três meses entre o término do grupo e o acompanhamento, para F2, pedia-se para considerar os três meses seguintes a F1 e, no último follow-up (F3), as perguntas eram respondidas considerando-se o intervalo de seis meses entre F2 e F3.

Os itens da CTS-2 são subdivididos em cinco classes: negociação (ações utilizadas para sair de uma discussão agressiva e iniciar um diálogo), violência psicológica (inclui agressões verbais e ameaças, entre outros), violência física (agressões contra o corpo do parceiro, utilizando ou não objeto externo), coerção sexual (comportamentos que buscam compelir o outro a se envolver em uma atividade sexual indesejada) e ferimentos (por exemplo, dores no corpo, cortes e fraturas ocorridos durante brigas).

- Entrevistas individuais com os agressores, recolhidas nas semanas iniciais do grupo para formar o perfil dos participantes. Tais entrevistas recolheram dados pessoais, estado emocional e de saúde, histórico familiar e dinâmica do relacionamento conjugal.

Quadro 1. Síntese dos temas e atividades desenvolvidos nas sessões do grupo.

\begin{tabular}{|c|c|}
\hline Sessão & Temas trabalhados $(\mathrm{T})$ e atividades realizadas $(\mathrm{A})$ \\
\hline 1 & $\begin{array}{l}\text { T: O que é psicologia; regras do grupo; o que é violência; tipos de violência; cronograma. } \\
\text { A: Dinâmica de apresentação, relaxamento. }\end{array}$ \\
\hline 2 & $\begin{array}{l}\text { T: Violência: responsabilidade, ciclo (Walker, 1979) e progressão; o agressor conjugal, relacionamento violento. } \\
\text { A: Relaxamento; aplicação da CTS-2. }\end{array}$ \\
\hline 3 & $\begin{array}{l}\text { T: Família de origem; impacto da violência na família; mitos sobre a mulher; defesas (negação, culpa). } \\
\text { A: Caracterização: famílias dos participantes e educação recebida; relaxamento. }\end{array}$ \\
\hline 4 & $\begin{array}{l}\text { T: Pensamento 'quente' (eleva a tensão) e 'frio' (reduz a tensão); controle da raiva. } \\
\text { A: Identificação de pensamentos 'frios' e 'quentes'; "time-out". }\end{array}$ \\
\hline 5 & $\begin{array}{l}\text { T: Papéis de gênero; comunicação; habilidades sociais (empatia, assertivo, inassertivo) } \\
\text { A: Treino em habilidades sociais (role-play); relaxamento. }\end{array}$ \\
\hline 6 & $\begin{array}{l}\text { T: Papéis de gênero (cont.) - estereótipos; comunicação (fazer e negar pedidos, mudança de comport.) } \\
\text { A: Treino de habilidades sociais (role-play). }\end{array}$ \\
\hline 7 & $\begin{array}{l}\text { T: Depressão e suicídio; avaliação e manutenção dos ganhos. } \\
\text { A: Feedback; reaplicação da CTS-2; relaxamento. }\end{array}$ \\
\hline 8 & $\begin{array}{l}\text { T: Avaliação do grupo; encerramento. } \\
\text { A: Questionário de Satisfação com o Tratamento, Entrevista de Avaliação da Intervenção Psicológica. }\end{array}$ \\
\hline
\end{tabular}


- Auto-relato semanal do participante sobre freqüência e intensidade das agressões, recolhido durante as sessões de grupo. Adicionalmente, os terapeutas anotavam os relatos que indicavam a utilização de estratégias trabalhadas na intervenção, permitindo acompanhar o desenvolvimento dos participantes.

- Instrumentos para avaliação do tratamento: 1) Questionário de Satisfação com o Tratamento (adaptado de Larsen, Attkinson, Hargreaves \& Nguyen, 1979) composto por sete questões fechadas, com quatro opções de escolha (de muito a nada satisfeito), que avalia o grau de satisfação do participante com relação à qualidade do atendimento recebido; e 2) Entrevista de Avaliação da Intervenção Psicológica (Williams, 2001a), aplicada aos participantes. Essa entrevista era composta por cinco questões abertas que requisitavam respostas quanto às motivações para participar do grupo, quanto à satisfação com o atendimento recebido e que pediam sugestões de alterações no grupo. Ambos os instrumentos foram aplicados na última sessão do grupo.

- Entrevista de Acompanhamento sobre o Relacionamento Conjugal (Williams, 2001a), aplicada nas parceiras antes, ao final do grupo e nos follow-ups, para recolher informações sobre a ocorrência de novas agressões ou ameaças, de nova denúncia na DDM, tipos de agressões sofridas, além de pedir uma descrição do relacionamento naquele dado momento.

- Monitoramento de registros de novas denúncias contra os participantes na DDM e confirmação das mesmas através de entrevistas com as respectivas parceiras.

\section{Resultados e Discussão}

A adesão dos participantes ao grupo foi a seguinte: P2 esteve presente em 100\% das sessões, P1 em 87,5\%, P4 em 66,7\%, P3 e P6 em 62,5\% e P5, por sua vez, obteve $50,0 \%$ de presença no programa de intervenção. As faltas foram comunicadas previamente ou justificadas na semana posterior. P7 participou das primeiras quatro sessões, deixando o grupo ao mudar de cidade após se separar da mulher.

Durante a entrevista inicial - caracterização dos agressores (Tabela 1), entre os participantes, quatro relataram histórico de violência durante a infância (P1, P4, P5, P6). Desses, três se referiram às agressões do pai contra a mãe e contra os filhos (P1, P4, P6) e um se referiu às agressões exclusivas do pai contra a mãe (P5). Outra característica encontrada entre os agressores foi a responsabilização da mulher pelas agressões, que pode ser bem ilustrada pelas seguintes verbalizações recolhidas: (mulheres) "pediam pra apanhar" ao "falar/reclamar demais".

As parceiras que participaram do pré-teste (PP1, PP2, PP3, PP4, PP6) revelaram ter sofrido violência, variando de uma a oito ocorrências no último semestre. Os tipos de violência física foram: empurrão (80\%), chute (60\%), tapa (60\%), soco (40\%) e puxão de cabelo, estrangulamento, apertões e atirar objetos (cada um com 20\%).

Segundo os relatos dos participantes recolhidos no início das sessões, não houve ocorrência de agressões contra as parceiras no decorrer do processo terapêutico. Nesse mesmo período, não houve registro de denúncias de agressão na DDM contra os participantes por parte de suas mulheres.

Tabela 1. Características dos participantes.

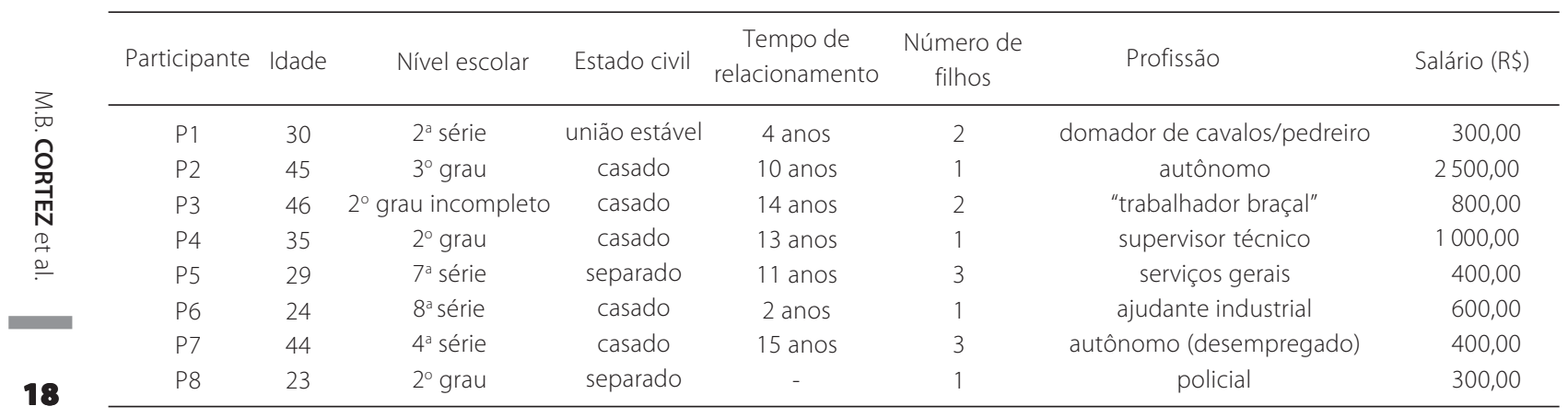


P4 e PP4 responderam apenas ao pré-teste, não fazendo parte do acompanhamento, alegando falta de tempo e desinteresse. P7 e sua ex-mulher não fizeram parte do acompanhamento por razões descritas anteriormente, mas, assim como o casal 4, ambos responderam ao pré-teste. P6 não possuía horário compatível para responder à CTS-2 em F1, F2 e F3, porém sua esposa respondeu ao F1 e F2.

Além de PP6, responderam ao F1: P1, P2, PP2 e P5. P3 não pôde participar de F1 por estar viajando, como informado por sua esposa. Em F2 e F3 participaram P1 e P2 e respectivas parceiras, sendo que P3 e P5 não puderam ser localizados.

Dentre os sete participantes que responderam à Escala de Táticas de Conflito Revisada (CTS-2), seis obtiveram maior pontuação na categoria violência psicológica, seguida por violência física e ferimentos produzidos na parceira. Apenas P6 registrou maior escore em violência física, seguida por violência psicológica e ferimentos. P6 foi também o único a pontuar na modalidade coerção sexual, registrando um ponto no item "insisti em fazer sexo sem usar força física". Seu relato foi o seguinte: "insisti, já continuei pedindo, mas se ela não quer...."

A Figura 1, a seguir, ilustra as relações entre a classe total de violência de cada participante nos pré- e pós-teste e em F1, F2 e F3.

Nota-se o decréscimo dos escores obtidos pelos participantes do pré-teste para o follow-up, o que sugere uma redução dos comportamentos agressivos e uma possível manutenção desses resultados.

Os participantes que obtiveram maior escore no total de violência foram P1 e P6. P1 obteve, do pré-teste para o pós-teste, uma redução de $98,5 \%$, sendo que do pré-teste para F2 e F3 a redução foi de 100,0\%. Os escores de $\mathrm{P} 2$ no total de violência tiveram redução de 100,0\% em F1 e F2, sendo que, em F3, um ano após o encerramento do grupo, $\mathrm{P} 2$ registrou 2 pontos na CTS-2, o que aponta para um aumento da agressividade em relação ao F1 e F2, mas que, comparando-se com o pré-teste, mantém-se expressivamente abaixo do escore inicial. P3 teve diminuição nos escores do préteste para o pós-teste, porém não pôde ser localizado para continuar o acompanhamento.

P5 também obteve diminuição de seus escores: do pré-teste para o pós-teste houve redução de 85,7\% e do pré-teste para F1 a redução do escore de total de violência foi de 100,0\%. Nesse caso, porém, o relato do participante pode estar caracterizando seu comportamento de negação com relação a seus atos agressivos, dado que contatos verbais realizados entre sua irmã e um dos terapeutas (um dos telefones de contato com P5 era o dela) indicavam a continuidade de comportamentos violentos dentro do ambiente familiar. A ex-esposa de P5 recusou-se a fazer parte do acompanhamento.

Assim como os escores dos participantes, as pontuações das parceiras demonstraram que, na maioria dos casos, a violência psicológica era a mais comum (PP1, PP2, PP3, PP4 e PP6), seguida pela violência física. PP7 foi a única a somar pontos na classe coerção sexual (nove no total), sendo que P7 não somou ponto algum nessa classe. Tal situação não pôde ser mais bem avaliada dado que P7 deixou o grupo. A Figura 2, a seguir, ilustra as relações entre os escores totais de violência das parceiras nos pré- e pós-teste e em F1, F2 e F3.

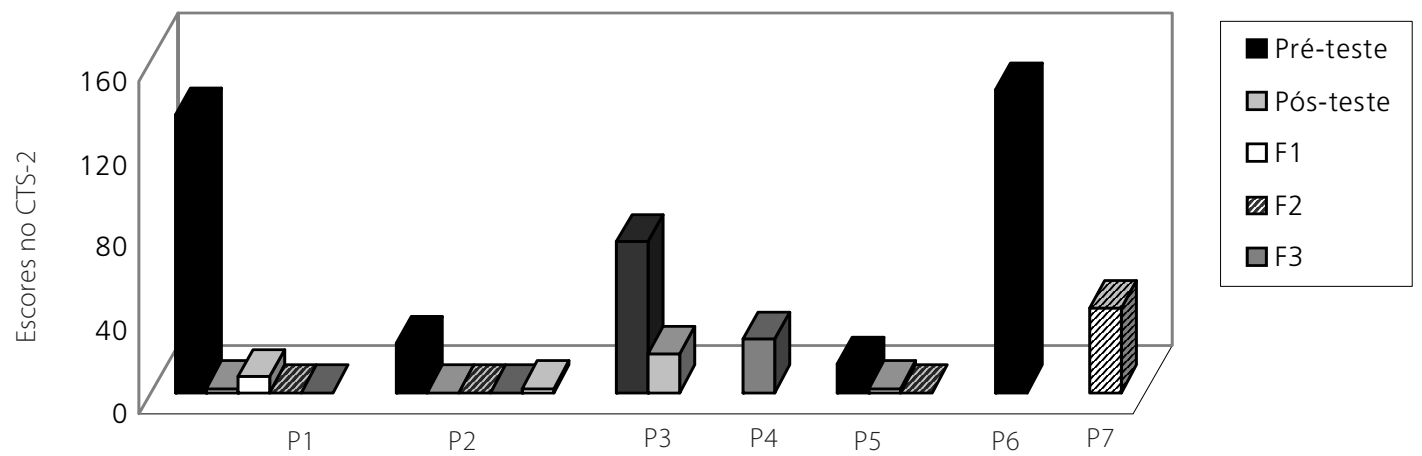

Figura 1. Escores dos participantes na classe 'total de violência', obtidos durante cada fase do estudo (agressões deferidas). 


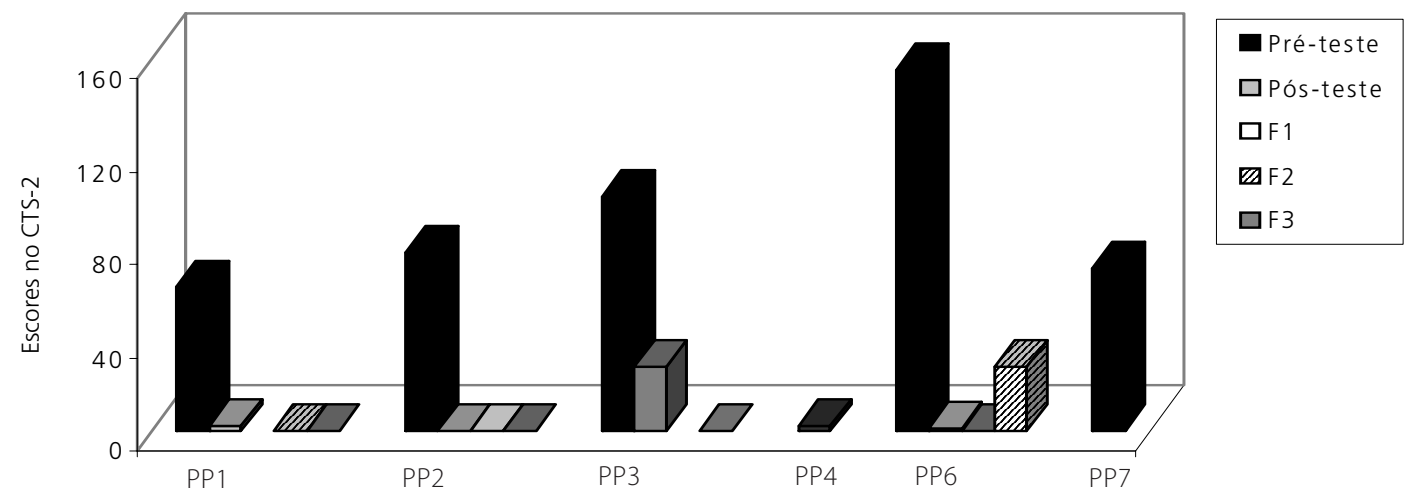

Figura 2. Escores das parceiras na classe 'total de violência', obtidos durante cada fase do estudo (agressões sofridas).

Os dados coletados com as parceiras corroboram com os fornecidos pelos participantes. Assim como na Figura 1, nota-se a redução dos escores obtidos pelas parceiras, comparando-se o pré-teste com o pós-teste. Os dados dos follow-ups de seis meses e um ano após o término do grupo revelam a manutenção da redução das agressões ao longo do tempo.

Nos três casos que puderam ser acompanhados, houve uma redução dos escores totais de violência do início do grupo para os períodos de follow-up, o que revela que as mulheres notaram e confirmaram a diminuição da violência após o grupo e a manutenção de tais resultados nas entrevistas em F1, F2 e F3.

PP1 não respondeu ao F1 dado que nesse período ficou temporariamente separada de P1 e não pôde ser localizada, porém seus escores em F2 e F3 são indicativos de uma manutenção dos ganhos e eliminação das agressões. Os escores de PP2 até o segundo follow-up apontavam a redução de 100\% das agressões, porém no follow-up de um ano (F3), confirmando a descrição de seu marido, PP2 revelou ter levado um "chute na canela" de P2. Apesar desse episódio, em um ano de acompanhamento essa foi a única agressão sofrida, indicando uma melhoria em termos do autocontrole do parceiro, o que é encorajador.

Os dados de PP6 em F1 indicaram redução das agressões. Já em F2, seis meses após o encerramento do grupo, seu escore aponta a reincidência de agressões, tendo PP6 relatado na entrevista de acompanhamento que, após duas agressões seguidas, interrompeu o relacionamento com P6 e voltou para a casa de seus pais.

\section{Conclusão}

Os participantes e suas parceiras avaliaram o grupo positivamente. O Quadro 2 contém alguns exemplos de suas verbalizações.

Quadro 2. Verbalizações de participantes e de suas parceiras, coletadas ao final do grupo ou no follow-up.

\begin{tabular}{lc}
\hline Relatos dos participantes & \multicolumn{1}{c}{ Relatos das parceiras } \\
\hline "mudei muito, passei a refletir mais, não ando tão tenso. Coloquei & "parou de beber quando entrou no grupo" "tá bom pai, bom \\
minha vida mais em ordem"; & marido, chega em casa e conversa" (PP2). \\
"tô vivendo em harmonia com (...) família" (P2). & "melhorou, ele começou a trabalhar, me ajuda com as menina" "se \\
"mudei muito, era um caboclo muito nervoso" & começa alguma briga, ele sai, volta depois (...) eu que começo", \\
"teve um dia que minha mulher começo a brigar e minha sogra falô & "agora nós tá feliz" (PP1). \\
que eu tinha mudado, senão já tinha brigado também" (P1). & "ele melhorou muito, tanto em relação a mim quanto ao menino" \\
"meus amigos do trabalho já perceberam que eu tô diferente, mais & "me ajuda, tá fazendo mais pelo menino..." (PP6). \\
calmo" (P6). & "de 0 a 10 acho que uns 6,5 ou 7, melhorou em termos sabe?"; "não \\
"é, eu tô pensando mais também, mais ainda às vezes eu encrenco" \\
(P3).
\end{tabular}


O grupo proposto mostrou-se uma estratégia de intervenção efetiva para alterar o comportamento violento do agressor conjugal, além de promover uma melhoria do ajustamento do casal.

\section{Referências}

Bandura, A. (1973). Aggression: A social learning analysis. Englewood Cliffs, NJ.: Prentice Hall.

Bandura, A., Ross, D., \& Ross, S.A. (1961). Transmission of aggression through imitation of aggressive models. Journal of Abnormal and Social Psychology, 63 (3), 575-82.

Faulkner, K., Stoltenberg, C.D., Cogen, R., Nolder, M., \& Shooter, E. (1992). Cognitive-behavioral group treatment for male spouse abuse. Journal of Family Violence, 7 (1), 37-55.

Gondolf, E.W. (1993). Male Batterers. In R.L. Hampson, T.P. Gullotta, G.R. Adams, E.H. Polter III \& R.P. Weissberg (Orgs.) Family Violence: Prevention and Treatment. Newbury Park: Sage Publications.

Gondolf, E.W. (1996a). Characteristics of batterers in a multiSite evaluation of batterer intervention systems: A Preliminary Report. Indiana: University of Pennsylvania.

Gondolf, E.W. (1996b). Characteristics of batterers in a multi-Site evaluation of batterer intervention systems: A summary of findings for a 12-month "follow-up". Indiana: University of Pennsylvania.

Gondolf, E.W. (1997). Characteristics of batterers in a multi-Site evaluation of batterer intervention systems: Summary of the 15-month "follow-up". Indiana: University of Pennsylvania.

Hamberger, L.K., \& Holtzworth-Munroe, A. (1999). Partner violence. In F.M. Dattilio \& A. Freeman (Orgs.). Cognitive Behavioral Strategies in Crisis Intervention (pp.302-324). London: The Guilford Press.

Hamby, S.L. (1998). Partner Violence: Prevention and intervention. In J.L. Jasinski \& L.M. Williams (Orgs.). Partner violence: A comprehensive review of 20 years of research (pp. 211-258). London: Sage Publications.

Jasinski, J.L., \& Williams, L.M. (1998). Partner violence: A comprehenvise review of 20 years of research. London: Sage Publications.

Larsen, D., Attkinson, C., Hargreaves, W., \& Nguyen, T. (1979). Assessment of client/patient satisfaction: Development of a general scale. Evaluation and program planning, 2, In E. Echeburúa. Vencendo a Timidez (pp.197-207). São Paulo: Mandarim.
O'Leary, K.D., Heyman, R.E., \& Neidig, P.H. (1999). Treatment of wife abuse: A comparison of gender-specific and conjoint approaches. Behavior Therapy, 30 (3) 475-505.

Padovani, R.C., Marcondelli, J., Gasparotto, M.C., \& Williams, L.C.A. (2001). Atendimento em grupo a mulheres agredidas pelo parceiro. In Anais da XXXI Reunião Anual de Psicologia. Rio de Janeiro.

Padovani, R.C., \& Williams, L.C.A. (2002). Intervenção psicoterapêutica com agressor conjugal: um estudo de caso. Psicologia em Estudo, 7 (2), 13-7.

Rynerson, B.C., \& Fishel, A.H. (1993). Domestic violence prevention training: Participant characteristics and treatment outcomes. Journal of Family Violence, 8 (3), 253-67.

Saffioti, H.I.B. (1997). Violência doméstica ou a lógica do galinheiro. In M. Kupstas (Org.). Violência em debate. São Paulo: Moderna.

Saffioti, H.I. (1999). A impunidade da violência doméstica. Notícias Fapesp.

Sinclair, D. (1985). Understanding wife assault: A training manual for counselors and advocates. Toronto: Publications Ontario.

Soares, B.M. (1999). Mulheres Invisíveis: violência conjugal e novas políticas de segurança. Rio de Janeiro: Civilização Brasileira.

Straus, M.A., Hamby, S.L., Boney-McCoy, S., \& Sugarman, D.B. (1996). The revised Conflicts Tactics Scale (CTS - 2). Journal of Family Issues, 17 (3), 283-316.

Walker, L. (1979). The Battered Woman. New York: Harper and Row.

Wexler, D.B. (1999). The broken mirror: A self psychological treatment perspective for relationship violence. The Journal of Psychotherapy Practice and Research, 8 (2), 129-145.

Williams. L.C.A. (2001a). The impact of reporting violence at a Brazilian Women's Police Station on female self-report of partner physical aggression. In M.Hertica (Coordenador), Legal and law enforcement issues in family violence. Simpósio apresentado no VI Congresso Internacional de Violência na Família, San Diego, California.

Williams, L.C.A. (2001 b). Violência doméstica: há o que fazer? In H.J. Guilhardi, P.P. Queiroz, N.B.B.P. Pinho \& A.L. Scoz (Orgs.). Comportamento e cognição (pp. 1-12). Santo André: ESETec Ed. Associados.

Recebido para publicação em 22 de junho de 2003 e aceito em 10 de janeiro de 2005 
